\title{
Minilaparoscopic Versus Conventional Laparoscopic Sacrocolpopexy: A Comparative Study
}

\author{
Hélder Ferreira, MD, ${ }^{1-3}$ Carlos Ferreira, MD, Cristina Nogueira-Silva, MD, $\mathrm{PhD}^{2,3,5}$ \\ Antonio Tomé, MD, PhD, Serafim Guimarães, MD, and Jorge Correia-Pinto, MD, PhD ${ }^{2,3,6}$
}

\begin{abstract}
Introduction and Aims: We aim to compare clinical and surgical outcomes between minilaparoscopic sacrocolpopexy (MLSC) and conventional laparoscopic sacrocolpopexy (LSC). As far as we know, no comparative study exists between these two minimal invasive procedures to correct vaginal prolapse.

Design and Setting: An observational and comparative study with 20 individuals submitted to vaginal vault prolapse correction between June and December of 2014 in our tertiary referral unit. Nine women were submitted to 3-mm MLSC and the others were approached by a standard 5-mm laparoscopic technique.

Materials and Methods: Women's demographic data and prolapse grade were evaluated preoperatively using the Pelvic Organ Prolapse Quantification score. Operative parameters (surgical time, blood loss, and complications under Satava and Clavien-Dindo classification) and length of hospitalization were also compared. Postoperative pain and surgical scar satisfaction were measured using Visual Analog Pain Scale and Patient and Observer Scar Assessment Questionnaire, respectively.

Results: MLSC took approximately the same time as LSC $(P>.05)$. No significant differences in operative time, blood loss, length of hospitalization, and complications (Satava, Clavien-Dindo) were observed between both groups. Pain score after surgery was similar in MLSC and LSC $(P>.05)$. Surgical scar monitoring at 3 months established that MLSC produced better overall results than LSC $(P<.05)$. Anatomic cure rate was $100 \%$.

Conclusion: Minilaparoscopy is a feasible and attractive approach for sacrocolpopexy as it enhances cosmetics, keeping the low morbidity associated with the classical laparoscopic approaches.
\end{abstract}

\section{Introduction}

$\mathbf{T}$ HE LIFETIME RISK of experiencing a single operation for prolapse or incontinence by age 80 was $11.1 \%$. Women seek treatment in an attempt to improve body image and quality of life. ${ }^{2}$ Many different surgical techniques to correct pelvic organ prolapse (POP) have been described in the past 60 years. The aim of this surgery is to restore physiologic anatomy as well as to preserve lower urinary tract, intestinal, and sexual functions. Sacrocolpopexy (SC) has shown superior outcomes for correcting apical prolapse after total hysterectomy when compared with a variety of other vaginal procedures, including sacrospinous colpopexy, uterosacral colpopexy, and transvaginal mesh. ${ }^{3} \mathrm{SC}$ was traditionally performed through an open abdominal approach associated with high rates of morbidity (longer time to return to daily activities, more postoperative pain, and unesthetic scars). Laparoscopic procedures in prolapse surgery have gained increasing importance within the past few years. Reduced morbidity, good cosmetic results, and a shorter stationary period are advantages generally offered by laparoscopy. ${ }^{4}$ With the continuous focus on minimizing the visibility of scars, new technological advances were developed to create smaller diameter endoscopes $(5 \mathrm{~mm})$ and surgical instruments $(3 \mathrm{~mm})$.

Observational data have revealed that minilaparoscopic cholecystectomy is associated with less postoperative analgesia

\footnotetext{
${ }^{1}$ Department of Obstetrics and Gynecology, Centro Hospitalar do Porto, Porto, Portugal.

${ }^{2}$ Life and Health Sciences Research Institute (ICVS), School of Health Sciences, University of Minho, Braga, Portugal.

${ }^{3}$ ICVS/3B's - PT Government Associate Laboratory, Braga, Guimarães, Portugal.

${ }^{4}$ Department of Urology, Hospital Pedro Hispano, Matosinhos, Portugal.

Departments of ${ }^{5}$ Obstetrics and Gynecology and ${ }^{6}$ Pediatric Surgery, Hospital de Braga, Braga, Portugal.
} 
and even better cosmesis when compared with traditional laparoscopic surgeries. ${ }^{5,6}$ During the last years, several minilaparoscopic procedures have been successfully performed in various surgical fields. ${ }^{7-10}$

Ultrahigh-definition cameras are appearing and the precision offered by this new image technology may push surgery to smaller instruments that allow a more accurate approach.

It was recently presented as the first case of minilaparoscopic SC, ${ }^{11}$ but, up to now, no comparative study exists between minilaparoscopic versus conventional laparoscopic sacrocolpopexy (LSC). We aim to report a short comparison of clinical and surgical outcomes between these two minimally invasive approaches.

\section{Materials and Methods}

This is a prospective, observational comparative study between patients who submitted to vaginal vault prolapse correction by 3-mm minilaparoscopic sacrocolpopexy (MLSC) and patients of identical characteristics treated by the conventional 5-mm laparoscopic approach. Inclusion criteria included BMI $<30$, aged 50-70 years, and symptomatic vault prolapse (minimally presenting as stage 2 prolapse of the apex or upper posterior wall of the vagina). Approval of the Local Ethics Committee was obtained.

\section{Preoperative evaluation}

Anatomic findings were scored according to the POP Quantification classification. $^{12}$

\section{Subjects}

Twenty patients participated in the protocol. For prolapse correction, nine women were assigned for a minilaparoscopic approach and 11 for a conventional 5-mm LSC technique. The study went on from June 2014 to December 2014.

\section{Decision of surgical technique}

The surgical technique was determined through a preferencebased, shared decision-making system. The patient was informed about the evidence to support the benefits and disadvantages of each available surgical choice. The surgeon did not recommend any specific surgical option to patients. According to the patient's preference and shared decision, the patient was allocated to either the LSC alone group or the MLSC group. All patients gave their informed consent. The same surgeon performed all surgical procedures.

\section{Surgical technique}

A first-generation cephalosporin was administrated to all patients 30 minutes before induction of general anesthesia in the supine position. The patient was prepped from the nipples to proximal thigh, including the vagina. The pneumoperitoneum was created using a Veress needle at an umbilical position up to $12 \mathrm{mmHg}$, where an optical trocar (30160GC; Karl Storz 6-mm trocar set; Karl Storz, Tuttlingen, Germany) was introduced and a 5-mm 30-degree endoscope (26046BA; HOPKINS II Forward Oblique telescope, Karl Storz) was used to have a general view of the abdominal cavity. After observing the pelvis, under direct visualization, three 3-mm ancillary trocars (30114GZL; Karl Storz minilaparoscopy trocar set) were inserted, one suprapubically and two laterally to the epigastric arteries, in the left and right lower abdominal quadrants, respectively (Fig. 1). The bowel was fixed to the left upper quadrant of the abdominal wall with a T-Lift ${ }^{\circledR}$ (VECTEC, Vichy, France) to better expose the right pelvis and the sacral promontory. A flat, flexible, handheld vaginal retractor was used to expose the vaginal cuff and facilitate the dissection. The vesicovaginal space was developed up to the bladder neck, which was identified using the balloon of the Foley catheter. Both pararectal fossa were opened by gentle
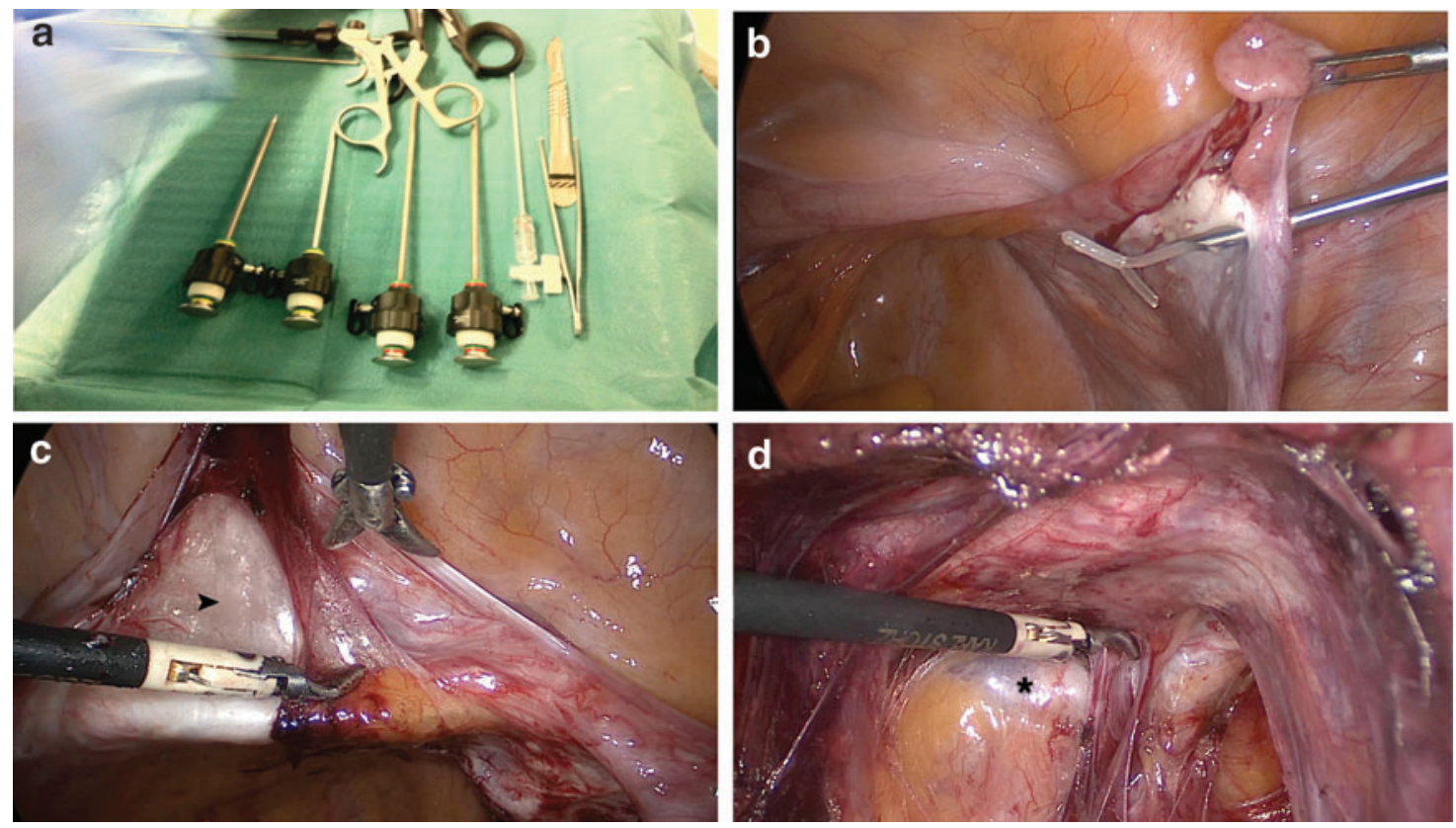

FIG. 1. (a) Minilaparoscopic trocars; (b) Right ovarian suspension with a T-Lift exposing right pararectal space; (c) Opening of the vesicovaginal space (arrowhead); (d) Opening of the rectovaginal space (asterisk). 
dissection up to the levator ani muscles. In these procedures, 36-cm-long minilaparoscopic instruments (Karl Storz Endoskope Minilaparoscopy Instruments Set) were used, choosing among graspers, cold scissors, suction/irrigation, and the recent 3.5-mm bipolar coagulator (Karl Storz Robi ${ }^{\circledR}$ ) (Fig. 1). Puborectalis muscles were exposed bilaterally using rotating bipolar forceps and a suction-irrigation device for blunt dissection, with identification of the middle rectal artery. The promomtorium was dissected with large exposition of the anterior sacral longitudinal ligament. The peritoneum was opened from promontorium up to the right uterossacral ligament, between the ureter and the right inferior hypogastric nerve. A wide dissection was performed. We used a polypropylene mesh (Gynemesh PS; Ethicon, Sommersville, NJ) that was cut in two parts, one for the anterior compartment and the other for the posterior compartment. The mesh and the sutures ( $26 \mathrm{~mm} \mathrm{1/2} \mathrm{circle} \mathrm{needle} \mathrm{Ethibond} \mathrm{Excel} \mathrm{suture;} \mathrm{Ethicon)} \mathrm{were}$ introduced in the abdominal cavity through the optical trocar. The anterior part has a terminal triangular shape and a long arm that comes up to the promontorium. The posterior part has a bifurcation to fix on both levator ani muscles (puborectalis) (Fig. 2).

The apex of the anterior triangular-shaped mesh was fixed in the dissected vesicovaginal space with a nonabsorbable, braided surgical suture comprising polyethylene terephthalate, Ethibond Excel suture (Ethicon). Sutures to the vagina were performed tangentially to minimize the risk of postoperative erosion of the suture material. The two arms of the posterior mesh were fixed with two Ethibond ${ }^{\circledR}$ sutures in both puborectalis muscles bilaterally.

A suture was used to fix the anterior mesh to the left uterosacral ligament and the posterior mesh, and a second suture was used to fix the anterior mesh to the right uterosacral ligament and the posterior mesh. The anterior and posterior meshes were used to replace the damaged fascias. After both meshes were attached, the long arm of the anterior mesh was fixed on the promontory with a unique suture that passed through all of the ligament thickness (Fig. 3).

The surgeon tested sacral fixation. The peritoneum involving the arm of the mesh was closed with a monofilament absorbable suture. All of the mesh was covered by peritoneum.

In the MLSC group, dissection, coagulation, and intracorporeal sutures were performed only with 3-mm instruments. Any small bleeding was immediately controlled with the bipolar instrument. The threads and needles were removed from abdominal cavity by a unique very small transabdominal hole using a BERCI fascial closure instrument (Karl Storz). This technique for suture removal was used to avoid excessive minitrocar manipulations that could interfere with the efficient performance of the procedure.

In the conventional laparoscopy group, 5-mm conventional laparoscopic instruments (Karl Storz Endoskope Instruments Set) were used and the technique was similar to the one described before with the smaller instruments.

All surgical endoscopic procedures were recorded on an AIDA $^{\circledR}$ (Advanced Image and Data Archiving System) device from Karl Storz.

Duration of operation was defined as the interval between the initial skin incision and skin closure. Intraoperative and postoperative surgical complications were classified as described by Satava ${ }^{13}$ and Dindo et al., ${ }^{14}$ respectively. Hospital stay was defined as the number of days spent in the hospital after surgery. Estimated blood loss was assessed from the contents of suction devices.

\section{Postoperative follow-up}

All patients were managed with the same standardized anesthetic protocol and postoperative analgesic therapy.
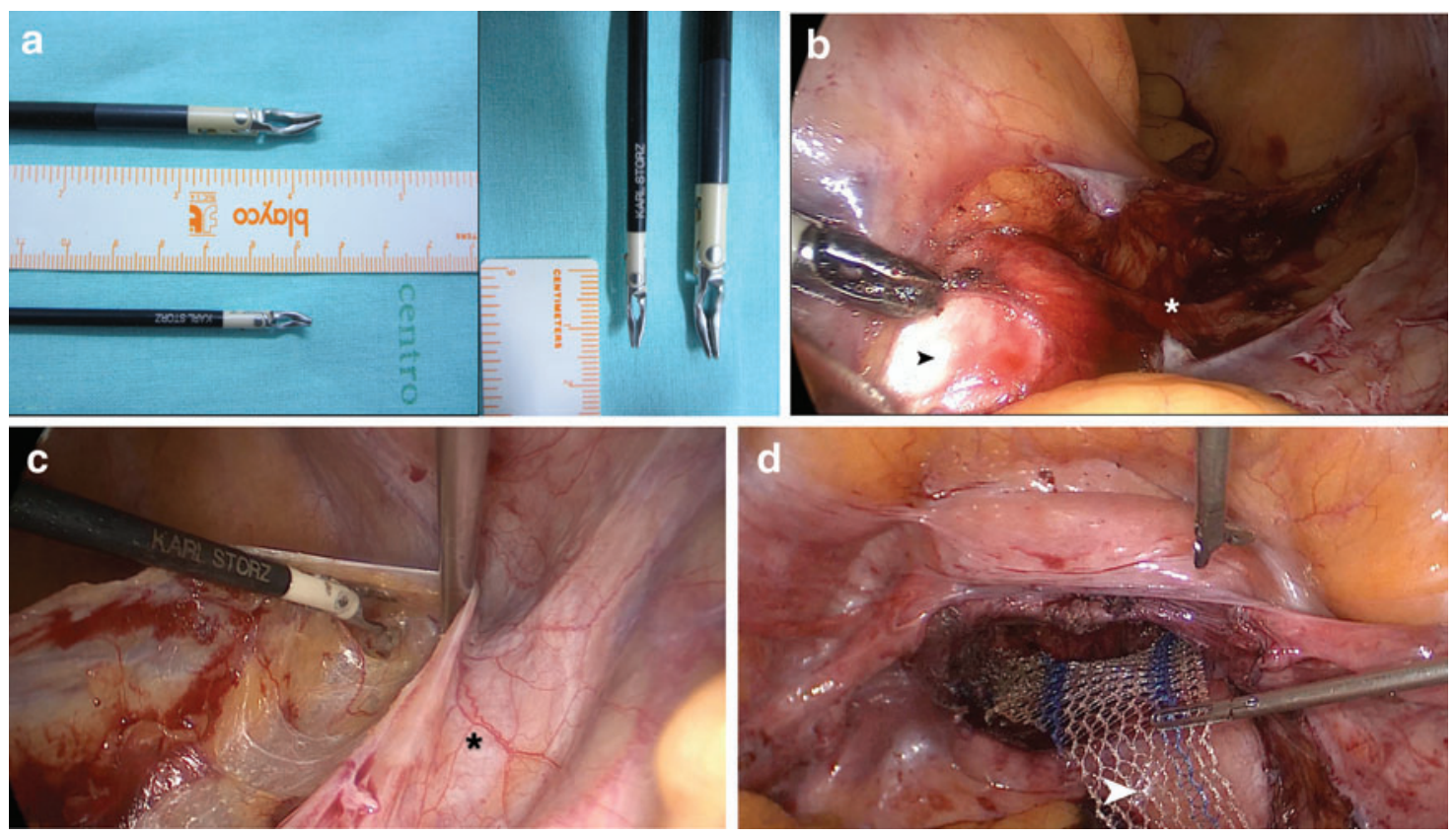

FIG. 2. (a) Minilaparoscopic versus conventional rotating bipolar dissectors; (b) Promontorium dissected: longitudinal sacral ligament (arrowhead), superior hypogastric nerve (asterisk); (c) Dissection of the right pararectal fossa, right ureter (asterisk); (d) Posterior mesh (arrowhead). 

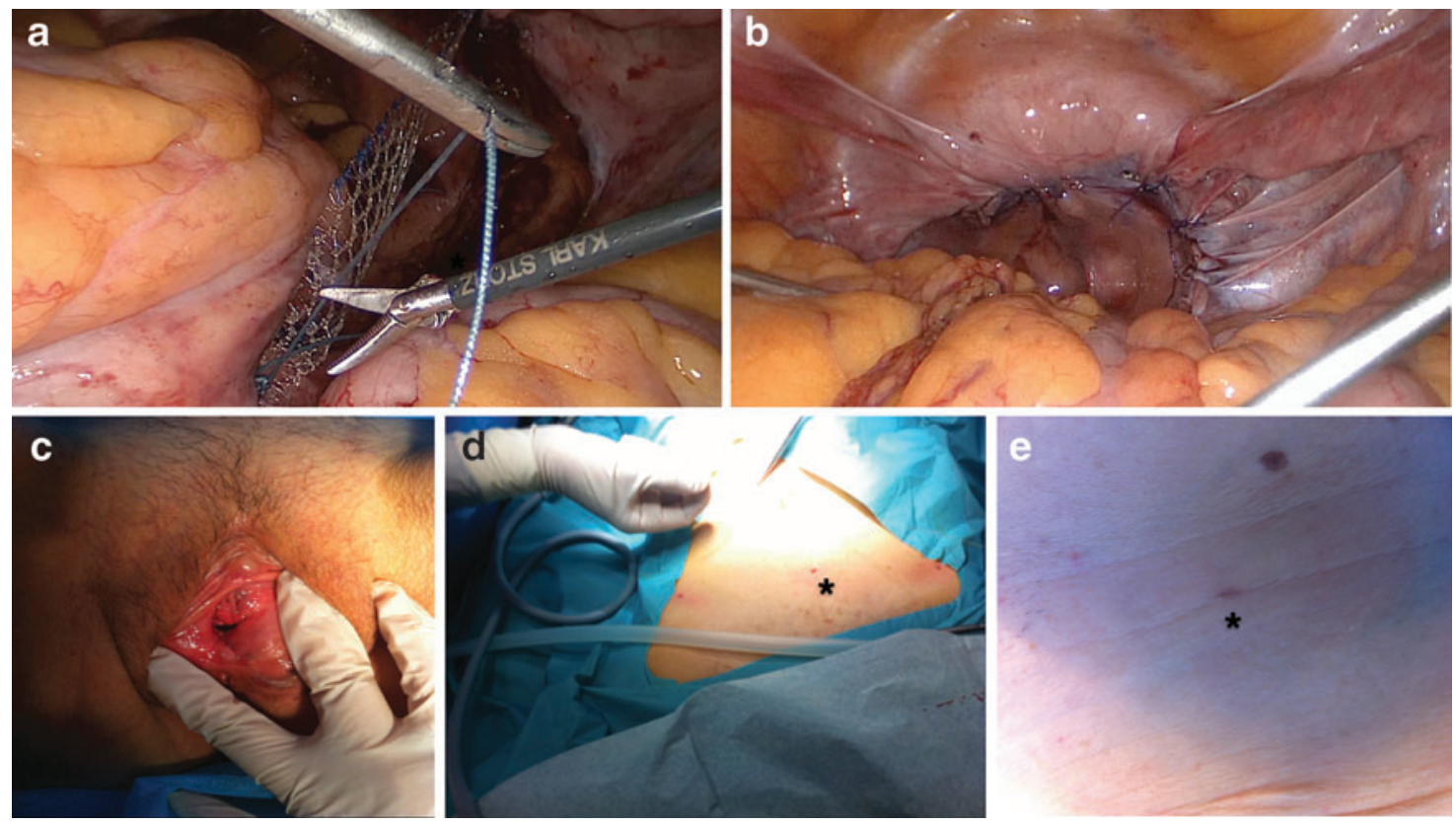

FIG. 3. (a) Cutting the thread that fixed the mesh to the promontorium; (b) Final view after mesh peritonization; (c) Anatomic cure 30 days after minilaparoscopic sacrocolpopexy; (d) scars (asterisk) immediately after 3-mm trocar removal; (e) scar assessment 7 days after surgery (asterisk).

Postoperative pain assessment (at 12 hours after surgery and at discharge) was performed in all patients by using a validated Visual Analog Pain Scale (VAPS) scored from 0 to $10(0=$ no pain; $10=$ agonizing pain $)$. Patients were allowed to go home when they were fully mobile, apyrexial, and passing urine satisfactorily.

The Patient and Observer Scar Assessment Questionnaire $(\text { POSAS })^{15}$ was filled by the patients and observer after 3 months on ambulatory regime. The observer was a blinded nurse that accepted to participate in the study. An ambulatory consultation and an anatomic assessment were also done after this period. De novo symptoms, defined as symptoms that were not present before surgery, but were present on subsequent visits, were evaluated. Anatomic cure, defined as the absence of stage II prolapse or more at any anatomical site, was also assessed.

\section{Statistical analyses}

The IBM ${ }^{\circledR}$ Statistical Package for Social Sciences (SPSS), version 20, was used for statistical analysis. Chi-square test was used for categorical variables. Age, body-mass index (BMI), operative time, blood loss, and hospital stay were compared using Student's $t$-test for independent groups. POSAS parameters were studied using the Mann-Whitney test. The criterion for statistical significance was set at $P<.05$ for all comparisons.

\section{Results}

Twenty patients underwent minimally invasive SC, 11 by conventional laparoscopy and nine by minilaparoscopy. All of them were performed by the same surgical team at our institution with the use of 5- or 3-mm instruments (Karl Storz), respectively. The two groups were similar with respect to sex, age, BMI, prolapse grade, and surgical history (Table 1).
Conventional LSC took approximately the same time as MLSC, 172 (148-197) minutes versus 166 (149-183) minutes; however, higher BMIs seem to be associated with longer operative times, mainly in the MLSC group $(P<.05)$. Four patients in the MLSC group were discharged home within less than 24 hours after surgery; however, no statistical differences were found between the two groups in terms of hospitalization length. There were no cases of middle sacral or pararectal fossa vessel bleeding and no bowel, bladder, or ureteral injuries. One patient, in the MLSC group, had a small bleeding from the vagina during the vesicovaginal dissection

Table 1. Clinical and Demographic Data

\begin{tabular}{|c|c|c|c|}
\hline & $\begin{array}{c}\text { Conventional } \\
\text { laparoscopic } \\
\text { sacrocolpopexy }\end{array}$ & $\begin{array}{c}\text { Minilaparoscopic } \\
\text { sacrocolpopexy }\end{array}$ & $\mathrm{P}$ \\
\hline Total patients, $n$ & 11 & 9 & ns \\
\hline $\begin{array}{l}\text { Mean age, } \\
\text { years (SD) }\end{array}$ & $60.7 \pm 7.5$ & $61.5 \pm 8$ & ns \\
\hline $\begin{array}{l}\text { Mean BMI, } \\
\mathrm{Kg} / \mathrm{m}^{2} \text { (SD) }\end{array}$ & $25.2 \pm 2.7$ & $24.1 \pm 2.7$ & ns \\
\hline \multicolumn{4}{|l|}{ POP-Q } \\
\hline I & - & - & ns \\
\hline II & 4 & 5 & ns \\
\hline III & 5 & 3 & ns \\
\hline IV & 2 & 3 & ns \\
\hline $\begin{array}{l}\text { Previous } \\
\text { abdominal } \\
\text { hysterectomy }\end{array}$ & 4 & 6 & ns \\
\hline $\begin{array}{l}\text { Previous vaginal } \\
\text { hysterectomy }\end{array}$ & 7 & 5 & ns \\
\hline Cesarean section & 8 & 4 & ns \\
\hline
\end{tabular}

BMI, body-mass index; ns, nonsignificant $(P>.05)$; POP-Q, Pelvic Organ Prolapse Quantification. 
immediately controlled by a minilaparoscopic bipolar dissector. Overall, there was no relevant intra- or postoperative complication (Table 2).

The pain scores (VAPS) at 12 hours after surgery and at discharge were similar in conventional laparoscopy and MLSC $(P>.05)$ (Table 3). At 3 months' consultation, patients were asymptomatic, the anatomic cure rate was $100 \%$, and there was a statistically significant reduction in nearly all the POSAS parameters when comparing LSC and MLSC $(P<.05)$ (Table 4).

\section{Discussion}

Laparoscopic surgery has developed rapidly in recent years. The LSC, which evolved from the classical abdominal SC, provides a shorter hospital stay, better hemostasis, and less pain than the open procedure. Better hemostasis is due to fine dissection and better visualization of the presacral, pararectal, and common iliac vessels. From a conceptual point of view, if abdominal SC corresponds to a palliative treatment of genital organ prolapse, the laparoscopic approach will actually provide a real reconstructive surgical procedure. ${ }^{16}$

A recent, randomized controlled trial confirmed that LSC is equally effective as open abdominal SC. ${ }^{17}$ With a recent emphasis on diminishing the visibility of scars, minilaparoscopy has reemerged as an appealing option for surgeons. As far as ML hysterectomy is concerned, Ghezzi et al. ${ }^{18}$ showed that ports could safely be reduced in size without a negative impact on the surgeon's ability to perform hysterectomy in patients with early-stage endometrial cancer. Our first reported cases of MLSC $^{11}$ have been reevaluated and they presented very positive anatomical and functional results.

The present preliminary study suggests that minilaparoscopy can be successfully and safely applied to SC for vaginal vault prolapse after hysterectomy, with similar perioperative outcomes compared with standard laparoscopy. In particular, no significant differences in operative time, blood loss, and pelvic prolapse correction, as well as complications

Table 2. Surgical Outcomes

\begin{tabular}{cccc}
\hline & $\begin{array}{c}\text { Conventional } \\
\text { laparoscopic } \\
\text { sacrocolpopexy }\end{array}$ & $\begin{array}{c}\text { Minilaparoscopic } \\
\text { sacrocolpopexy }\end{array}$ & $\mathrm{P}$ \\
\hline $\begin{array}{c}\text { Mean operative } \\
\text { time, minutes } \\
\text { (range) }\end{array}$ & $166(149-183)$ & $172(148-197)$ & $\mathrm{n}$ \\
$\begin{array}{c}\text { Mean operative } \\
\text { blood loss, } \\
\text { mL (range) }\end{array}$ & $80(55-115)$ & $75(50-130)$ & $\mathrm{n}$ \\
$\begin{array}{c}\text { Mean hospital } \\
\text { stay, days (SD) }\end{array}$ & $2.2 \pm 0.6$ & $1.7 \pm 0.64$ & $\mathrm{n}$ \\
$\begin{array}{l}\text { Intraoperative complications } \\
\text { None }\end{array}$ & & \\
$\begin{array}{l}\text { Satava grade 1 } \\
\text { Satava grade 2 }\end{array}$ & 11 & 8 & $\mathrm{n}$ \\
$\begin{array}{c}\text { Postoperative complications } \\
\text { None }\end{array}$ & 0 & 1 & $\mathrm{n}$ \\
$\begin{array}{l}\text { Clavien-Dindo } \\
\text { grade I }\end{array}$ & 11 & 0 & $\mathrm{n}$ \\
$\begin{array}{l}\text { Clavien-Dindo } \\
\text { grade II }\end{array}$ & 0 & 9 & $\mathrm{n}$ \\
$\quad 0$ & 0 & $\mathrm{n}$ \\
\hline
\end{tabular}

Table 3. Pain Assessment

\begin{tabular}{lccc}
\hline & $\begin{array}{c}\text { Conventional } \\
\text { laparoscopic } \\
\text { sacrocolpopexy }\end{array}$ & $\begin{array}{c}\text { Minilaparoscopic } \\
\text { sacrocolpopexy }\end{array}$ & $\mathrm{P}$ \\
\hline $\begin{array}{l}\text { VAPS } \\
\begin{array}{l}\text { Postoperative } \\
\quad 2 \text { hours }\end{array}\end{array}$ & $2.36(0.81)$ & $2.09(0.94)$ & $\mathrm{ns}$ \\
\begin{tabular}{l} 
Discharge \\
\hline
\end{tabular} & $1.1(0.7)$ & $0.81(0.75)$ & $\mathrm{ns}$ \\
\hline
\end{tabular}

VAPS, Visual Analog Pain Scale (0-10 Numeric Pain Rating Scale).

(Satava, Clavien-Dindo), were observed between LCSC and MLSC groups.

The shorter hospital stay in the minilaparoscopic group may be a cost-effective alternative in the way that it may be scheduled in an ambulatory surgery regime $(<24$ hours of hospitalization).

In a prospective comparative study, Porpiglia et al. showed that patients who underwent minilaparoscopic pyeloplasty were significantly more satisfied with their cosmetic outcomes than those who were submitted to a standard laparoscopic approach. ${ }^{19}$ A better cosmetic outcome using smaller trocars has also been reported in general surgery literature through comparative studies on standard laparoscopic cholecystectomy. ${ }^{5,20}$ At 3 months' consultation, after POSAS Questionnaire, ${ }^{15}$ we reported significantly better scores in the MLSC group than in the patients approached by traditional laparoscopic instruments.

Possible mystifications regarding 3-mm instruments may include poor grasping ability, weak manipulation, and difficulty during dissection and development of anatomical spaces. ${ }^{8,10}$ Nevertheless, several investigations in the field of gynecologic and nongynecologic surgery suggest that downsizing abdominal ports allows equal or better surgical results compared with standard laparoscopic procedures. ${ }^{9,21-24}$ In addition, the use of small-diameter laparoscopes and instruments

Table 4. Minilaparoscopic and Laparoscopic Patient and ObSERVER SCAR AsSessment Questionnaire Values (Mann-Whitney Test for Statistical Analysis)

\begin{tabular}{lccc}
\hline & $\begin{array}{c}\text { Conventional } \\
\text { laparoscopic } \\
\text { sacrocolpopexy } \\
\text { (median value) }\end{array}$ & $\begin{array}{c}\text { Minilaparoscopic } \\
\text { sacrocolpopexy } \\
\text { (median value) }\end{array}$ & P \\
\hline Varameter & 3 & 2 & .2 \\
Pascularity & 4 & 1 & .05 \\
Thickntation & 4 & 2 & .03 \\
Relief & 4 & 2 & .02 \\
Pliability & 4 & 2 & .06 \\
Overall & 4 & 2 & .03 \\
$\quad$ (observer) & 3 & 2 & .08 \\
Pain & 3 & 2 & .12 \\
Itching & 5 & 3 & $<.01$ \\
Color & 4 & 2 & .02 \\
Hardness & 4 & 2 & $<.01$ \\
Thickness & 5 & 2 & .01 \\
Shape & 4 & 2 & .01 \\
Overall & & & \\
$\quad$ (patient) & & & \\
\hline
\end{tabular}


is feasible with low carbon dioxide pressures, ${ }^{25}$ thereby reducing possible complications related to pneumoperitoneum.

We recognize some specificities and possible limitations of minilaparoscopic instruments, such as higher susceptibility to bending, resulting in an increased difficulty when dissection is carried out on a very hard fibrous tissue. Obesity may represent a challenge to minilaparoscopic instruments because intraperitoneal access could be more demanding and low insufflation pressures can be insufficient to lift the weight of the abdomen and provide a good view. However, these potential technical problems did not alter our ability to safely and effectively perform MLSC. In the present study, we observed that minilaparoscopic instruments were very efficient in suturing vessels and nerve identification, allowing precise hemostasis and nerve preservation.

We can assume that the adequacy of SC is mainly determined by the expertise of the surgeon rather than by the caliber of the instruments used. Indeed, we decided to adopt a minilaparoscopic approach to SC only after overcoming our learning curve with conventional laparoscopy. Under this view, our findings must be interpreted cautiously since generalization of these results in less experienced hands is far from guaranteed. Finally, costs of minilaparoscopic instruments overlap conventional ones, although with expected shorter durability. The smaller incisions and miniature tools involved in minilaparoscopy may provide somewhat better cosmetic results and shorter hospital stays that should be balanced at the end.

In a very short future, the new ultrahigh-definition cameras will succeed in surgery, therefore more precise and delicate instruments must follow this better image resolution. We are firmly convinced that these minilaparoscopic instruments will have a strong role in this next video camera generation. It will be possible to join a more accurate picture to a more precise tool. As described recently, LSC should be a nervesparing technique. ${ }^{26}$ This more precise combined approach will help in nerve preservation and other anatomical delicate structure identification.

Some study limitations should be acknowledged such as the sample size and the absence of randomization. The experience with this technique is very small and follow-up limited. Despite these restraints, to the best of our knowledge, this represents the first study that compares minilaparoscopic versus LSC using validated assessment tools (i.e., POSAS, VAPS) and our results indicate that the ML approach might offer a better surgical scar from the patient's and observer's point of view. Thus, further studies are necessary in this field.

By reproducing the principles of standard laparoscopy, and with predictable improvements of 3-mm instruments and higher definition cameras, we predict that MLSC can be regarded as an excellent option to POP correction.

\section{Conclusions}

Minilaparoscopy is a feasible and attractive approach for $\mathrm{SC}$ as it enhances cosmetics, keeping the low morbidity associated with the classical laparoscopic approaches.

\section{Acknowledgment}

The authors acknowledge Karl Storz for their support with equipment.

\section{Disclosure Statement}

No competing financial interests exist.

\section{References}

1. Olsen AL, Smith VJ, Bergstrom JO, Colling JC, Clark AL. Epidemiology of surgically managed pelvic organ prolapse and urinary incontinence. Obstet Gynecol 1997;89: 501-506.

2. Jelovsek JE, Barber MD. Women seeking treatment for advanced pelvic organ prolapse have decreased body image and quality of life. Am J Obstet Gynecol 2006;194:1455-1461.

3. Maher C, Feiner B, Baessler K, Schmid C. Surgical management of pelvic organ prolapse in women. Cochrane Database Syst Rev 2013;4:CD004014.

4. Hsiao KC, Latchamsetty K, Govier FE, Kozlowski P, Kobashi KC. Comparison of laparoscopic and abdominal sacrocolpopexy for the treatment of vaginal vault prolapse. J Endourol 2007;21:926-930.

5. Novitsky YW, Kercher KW, Czerniach DR, Kaban GK, Khera S, Gallagher-Dorval KA, et al. Advantages of minilaparoscopic vs conventional laparoscopic cholecystectomy: Results of a prospective randomized trial. Arch Surg 2005;140:1178-1183.

6. Cheah WK, Lenzi JE, So JB, Kum CK, Goh PM. Randomized trial of needlescopic versus laparoscopic cholecystectomy. Br J Surg 2001;88:45-47.

7. Porpiglia F, Autorino R, Cicione A, Pagliarulo V, Falsaperla M, Volpe A, et al. Contemporary urologic minilaparoscopy: Indications, techniques, and surgical outcomes in a multiinstitutional European cohort. J Endourol 2014;28:951-957.

8. Berci G. Laparoscopic cholecystectomy using fine-caliber instruments. Smaller is not necessarily better. Surg Endosc 1998;12:197.

9. Liao CH, Lai MK, Li HY, Chen SC, Chueh SC. Laparoscopic adrenalectomy using needlescopic instruments for adrenal tumors less than $5 \mathrm{~cm}$ in 112 cases. Eur Urol 2008; 54:640-646.

10. Gagner M, Garcia-Ruiz A. Technical aspects of minimally invasive abdominal surgery performed with needlescopic instruments. Surg Laparosc Endosc 1998;8:171-179.

11. Ferreira H, Ferreira C, Braga A, Pereira AT, Guimaraes S. Minilaparoscopic sacrocolpopexy for vaginal prolapse after hysterectomy. Surg Technol Int 2014;25:157-161.

12. Bump RC, Mattiasson A, Bo K, Brubaker LP, DeLancey $\mathrm{JO}$, Klarskov P, et al. The standardization of terminology of female pelvic organ prolapse and pelvic floor dysfunction. Am J Obstet Gynecol 1996;175:10-17.

13. Satava RM. Identification and reduction of surgical error using simulation. Minim Invasive Ther Allied Technol 2005;14:257-261.

14. Dindo D, Demartines N, Clavien PA. Classification of surgical complications: A new proposal with evaluation in a cohort of 6336 patients and results of a survey. Ann Surg 2004;240:205-213.

15. van de Kar AL, Corion LU, Smeulders MJ, Draaijers LJ, van der Horst CM, van Zuijlen PP. Reliable and feasible evaluation of linear scars by the Patient and Observer Scar Assessment Scale. Plast Reconstr Surg 2005;116:514-522.

16. Gadonneix P, Ercoli A, Scambia G, Villet R. The use of laparoscopic sacrocolpopexy in the management of pelvic organ prolapse. Curr Opin Obstet Gynecol 2005;17:376-380.

17. Freeman RM, Pantazis K, Thomson A, Frappell J, Bombieri $\mathrm{L}$, Moran $\mathrm{P}$, et al. A randomised controlled trial of abdominal versus laparoscopic sacrocolpopexy for the treatment of 
post-hysterectomy vaginal vault prolapse: LAS study. Int Urogynecol J 2013;24:377-384.

18. Ghezzi F, Cromi A, Siesto G, Uccella S, Boni L, Serati M, et al. Minilaparoscopic versus conventional laparoscopic hysterectomy: Results of a randomized trial. J Minim Invasive Gynecol 2011;18:455-461.

19. Fiori C, Morra I, Bertolo R, Mele F, Chiarissi ML, Porpiglia F. Standard vs mini-laparoscopic pyeloplasty: Perioperative outcomes and cosmetic results. BJU Int 2013;111: E121-E126.

20. Bisgaard T, Klarskov B, Trap R, Kehlet H, Rosenberg J. Microlaparoscopic vs conventional laparoscopic cholecystectomy: A prospective randomized double-blind trial. Surg Endosc 2002;16:458-464.

21. Quattrone C, Cicione A, Oliveira C, Autorino R, Cantiello F, Mirone V, et al. Retropubic, laparoscopic and minilaparoscopic radical prostatectomy: A prospective assessment of patient scar satisfaction. World J Urol 2015;33: 1181-1187.

22. Ghezzi F, Cromi A, Siesto G, Boni L, Uccella S, Bergamini $\mathrm{V}$, et al. Needlescopic hysterectomy: Incorporation of 3$\mathrm{mm}$ instruments in total laparoscopic hysterectomy. Surg Endosc 2008;22:2153-2157.

23. Mamazza J, Schlachta CM, Seshadri PA, Cadeddu MO, Poulin EC. Needlescopic surgery. A logical evolution from conventional laparoscopic surgery. Surg Endosc 2001;15: 1208-1212.

24. Nicolay LI, Bowman RJ, Heldt JP, Jellison FC, Mehr N, Tenggardjaja $\mathrm{C}$, et al. A prospective randomized comparison of traditional laparoendoscopic single-site surgery with needlescopic-assisted laparoscopic nephrectomy in the porcine model. J Endourol 2011;25:1187-1191.

25. Bogani G, Uccella S, Cromi A, Serati M, Casarin J, Pinelli $\mathrm{C}$, et al. Low vs standard pneumoperitoneum pressure during laparoscopic hysterectomy: Prospective randomized trial. J Minim Invasive Gynecol 2014;21:466-471.

26. Sarlos D, Aigmueller T, Magg H, Schaer G. Laparoscopic sacrocolpopexy: Demonstration of a nerve-sparing technique. Am J Obstet Gynecol 2015;212:824.e1-e3.

Address correspondence to: Hélder Ferreira, MD Department of Obstetrics and Gynecology Centro Hospitalar do Porto Rua Júlio Dinis, $n^{\circ} 230, B-2,9^{\circ} E s q$ Porto 4050-318

Portugal

E-mail: helferreira@hotmail.com 